\title{
Genre and Subjectification in Janine Antoni’s Loving Care
}

\author{
Johanna Morgan Boyes ${ }^{\mathrm{a}}$
}

In her 2008 book, The Female Complaint: The Unfinished Business of Sentimentality in Popular Culture, Lauren Berlant writes, "femininity is a genre... an aesthetic structure of affective expectation... promising that the persons transacting with it will experience the pleasure of encountering what they expected, with details varying in the theme". This perspective provides a grounding for Berlant to argue that popular culture offers conventions of female experience marked by sentimentality, specifically, the disappointments in the relationship between fantasy and lived intimacy. Central to Berlant's work is a desire for conventionalitythrough adherence to convention, one becomes a social subject. This echoes but is distinct from the work of poststructuralists, who regards the assumption of a sexual identification as how one moves out of the abject into the social realm. The interaction between an individual and the genre of femininity as domestic, intimate, and emotionally fraught is useful to understanding Janine Antoni's 1993 performance Loving Care. In Loving Care, the artist dipped her hair in a bucket of black hair dye and, on her hands a knees, used it to mop the floor. This essay will argue that Antoni's performance is a self-conscious reiteration (and exaggeration) of feminine convention. Through dying hair and mopping, Loving Care shows the desire to become a social subject, a woman. Through representations, womanhood has developed a shared understanding of being inherently straining and tenuous, with its obligations of beauty and emotional labor as prerequisite to social belonging and desirability. Antoni's performance will be analyzed as an experience imagined by the viewer, one that attempts to perform the process of the formation of a subjectivity.

Keywords: Performance art; body art; post-structuralism; literary theory; genre; affect theory

As Amelia Jones describes in Body Art/Performing the Subject (1998), the presence of the artist's body resists formalist analysis, calling attention to intentionality, embodiment, and desire inhering in an artwork's production and reception (5). The emergence of performance art in the second half of the 20th century speaks to a shift away from the modernist concept of the subject as complete within itself, coherent, and centered, toward a postmodern emphasis on intersubjectivity. Within modernism, the artist is a master of intentionality who produces a discrete work to be evaluated by a disinterested, formal art history. The performance artist disrupts the modernist subject by bringing to the forefront the embodiment of artistic production, implicated as a situated, social act. The presence of the body shows that the body cannot be "known 'purely' as a totalizing, fleshy whole that rests outside the area of the symbolic" (O'Dell 1992 43-4), that the body/self always holds a symbolic place in culture. In performance art, the unknowable, representational body becomes a sign in a process of interpretation, contingent upon receptive context and intersubjective relation between spectator(s) and artist. To call performance art postmodern highlights the awareness and purposefulness with which the artist enacts the contingency inhering in the process of subjectification outlined in post-structuralist thought. Said another way, the postmodern subject in performance art is selfconsciously engaged with the totalizing, discursive, reproducing social order described by post-structuralists.

In "Feminist Interventions in the History of Art" (1998), Griselda Pollock writes:

"Feminist artistic practices and texts have intervened in alliance with other radical groups to disrupt the hegemony of modernist theories and practices even now still active in art education in the so-called postmodernist culture. They have done this not merely to make a place for women artists within the art world's parameters. The point is to mount a sustained and far reaching political critique of contemporary representational systems which have an overdetermined effect in the social production of sexual difference and its related gender hierarchy." (13)

The production of subjectivities of gender through artistic representation is as relevant to activistic and/or self-conscious art as art more obviously implicated in hegemonic inequalities. Janine Antoni's 1993 Loving Care is a fruitful example for analyzing purposeful, artistic subjectification. In Loving Care, Antoni dipped her long hair in black hair dye and, on her hands and knees, mopped the floor with it. The gender-coded objects and behaviors which constitute this work, as well as its embodied, performative, reiterative aspects, align with poststructuralist concepts of the process of subjectification. This article will offer theoretical groundwork to account for the intentionality of the postmodern subject in artwork which deals with post-structuralist themes. It can be argued that Antoni's deeply conventionalized and reiterative performance is best understood through a model of femininity as genre.

Extending Amelia Jones' theories on the intersubjective exchange, Loving Care will be analyzed at the level of the experiential rather than the pictorial. In this sense, the focus on this work is concerned with the process of mopping the floor, both real (for the artist) and imagined (by the spectator and artist). Rather than evaluating the signification of the mopped floor, Loving Care is meaningful as an act one performs, witnesses, or imagines as a process of identification. As Rosalind Krauss writes, "identity (self-definition) is primally fused with identification (a felt connection to someone else)" (1986 197). For the spectator and the artist, the artist's body is the Other upon which one projects in the formation of self. This aligns with theoretical elaborations on Lacan's mirror stage which argue that one enters the realm of the discursive and symbolic through defining Self with and against the other. This identification with the artist's body as Other regards the body as a sign, which even (and perhaps, especially) in its 
absence is meaningful as a tool of identification, even when Antoni's mopping of the floor is imagined rather than witnessed directly. It is in this specific focus on the experiential element of Loving Care that gives rise to a diversion from the perspective held by the editors of October in the 1993 roundtable "The Reception of the Sixties". Their focus on the "residue" (Carson 145) of Antoni's performance places Loving Care in the context of minimalism, arguing that Antoni's work aims to critique the lack of emotion in 1960s minimalist art. The editors place Antoni's work in a genealogy of modernism, insisting that Loving Care is a failed attempt to feminize a problematic tradition of the embodied and dominating modernist artist. A difference of opinion is seen from this approach by rejecting a focus on the mopped floor as a sign functioning congruously to Jackson Pollock's finished canvas. An investigation into Antoni's work shifts toward the experience of the process itself. A useful distinction can be made between this article and this art historical method that can be illustrated by examining Bett Schumacher's writing on Helen Frankenthaler. In "The Woman Problem: Gender Displacement in the Art of Helen Frankenthaler" (2010), Schumacher examines Frankenthaler's canvas and immediately connects it to an imagined embodied process of its creation. This allows Schumacher to compare the discursive rendering of Frankenthaler's artistic process with Pollock. The absence of the body highlights or, in psychoanalytic terms, fetishizes the artist's body. Antoni, by contrast, was present for Loving Care.

The method presented here aligns more closely with Juli Carson, who responded to the October roundtable arguing for a psychoanalytic perspective. Carson writes about Loving Care as playing out "desire of repetition-compulsion as it relates to elusive notions of mastery over one's own subjectivity" (144). Carson cites how Loving Care was initially conceived for a 1992 exhibition of feminist and queer reconfigurations of Freudian notions of the fetish. She writes that the work was originally just the "residue" of the ritual, but eventually, Antoni shifted to performing Loving Care. For Carson, Antoni's absence served to spectacularize and fetishize her body, while her presence more successfully communicated the ritual itself as the fetish. In the language of psychoanalysis, Carson points out repetition as formative of subjectivity, which I would like to take further and place in the terms of a collective experience of subject formation for both the artist and the spectator, as well as open up a space to discuss the affective components of Antoni's performance. This collective, affective formation occurs through the conventionalized nature of Antoni's representation of femininity. In modifying the psychoanalytic perspective and arguing for a genre model, a framework for understanding performance art which resists the modernist genealogy of Pollock is offered.

In The Female Complaint: The Unfinished Business of Sentimentality in American Culture (2008), Lauren Berlant writes that genre is "an aesthetic structure of affective expectation, an institution or formation that absorbs all kinds of small variations or modifications while promising that the persons transacting with it will experience the pleasure of encountering what they expected, with details varying in the theme". She argues that femininity is a genre, writing, "to call an identity like a sexual identity a genre is to think about it as something repeated, detailed, and stretched while retaining its intelligibility, its capacity to remain readable or audible across the field of all its variations." (4) Berlant's theory outlines the ways in which popular culture offers conventionalized representations of women's experiences to produce a sense that before these representations, there existed a world of strangers who would be emotionally literate in each other's experience of power, intimacy, desire, and discontent. Femininity becomes a genre that claims emotional generalities about women's experiences despite differences between individuals, classes, and races. Through offering a sense of belonging, conventional structures of feminine affectation manage ambivalence about the experiences of womanhood.

Berlant is careful in her discussion of the ambivalence of womanhood, explaining that women are an example of "a collectivity historically created by biopower, class antagonism, nationalism, imperialism, and/or the law and, at the same time.. engendered by an ongoing social life mediated by capital and organized by all kinds of pleasure" (8). Womanhood gains a sense of coherence through repetition of convention, coalescing into a kind of collective memory defined by "the pleasures, burdens, and virtues of emotional expertise." (2) To transact with convention assures, intensifies, and legitimates "qualities, ways of being, and entire lives", creating "situations where those qualities can appear as luminous" (3).

Berlant describes public-sphere femininity as a "love affair with conventionality" (2), in which a coherent sense of women's universal experience are offered in service of the "desire of a complex person to rework the details of her history to become a vague or simpler version of herself" (7), as well offering as "soft supremacy" (6) which dissolves other forms of difference. She writes, "to be competent in a genre is therefore to be cultivated as a certain kind of subject, a type." (260)

Genre as transactional aligns with Amelia Jones' writing on the intersubjective exchange at the core of performance art. Antoni and her audience engage with an affected, exaggerated, full-bodied structure of the deeply conventional, gendered activities of domestic labor and transformative beautification (arguably, also a form of labor). Antoni performed Loving Care toward the end of second wave feminism, a project with a focus on representing women's life in the domestic space with drama and intensity. Though Berlant generally wrote about middlebrow literature in her discussion of genre, one could argue that second wave feminism similarly collapsed the differences of women's experiences into a collective imaginary of universal femininity. Betty Friedan's The Feminine Mystique mentions hair dye several times, including a reference to a 1960 magazine article discussing "the 'increasing baldness in women.' caused by too much brushing and dyeing." (17). Friedan mentions that in the second half of the twentieth century in America, "woman's world was confined to her own body and beauty." Loving Care's use of extremely conventional behaviors as constitutive of femininity draws from the singular, coherent narrative of womanhood outlined by second wave feminist thought by writers like Friedan, De Beauvoir, or Greer. For Antoni to laboriously mop the floor on her knees, she attempts to "become a woman"induct herself into an imaginary collectivity of shared experience. Though that shared experience involves pain and ambivalence, Berlant's model holds that the induction into a collectivity is a type of pleasure. 
To further the analysis of Loving Care's decided conventionality, Antoni's use of her hair is analyzed in this laborious process. Antoni's use of commercially-available Loving Care hair dye with her long hair speaks to culturally and historically entrenched political and gendered meanings. In "Shame and Glory: A Sociology of Hair", Anthony Synnott writes that "hair is perhaps our most powerful symbol of individual and group identity- powerful first because it is physical and therefore extremely personal, and second because although personal, it is also public rather than private" (381). Synnott's work is useful in analyzing the emergence of an individual into categories of social meaning, pointing out that a theory of hair can be "called a theory of opposites", summarizing three positions of symbolic practice: opposite sexes have opposite hair, head hair and body hair are opposite, and opposite ideologies have opposite hair. (382) According to Synnott, the symbolism of long hair as tied with femininity and female sexuality has been a part of North American and British culture for centuries. Further, it is worth pointing out that hair dye is transformative (formative), veiling, and commercially available.

As discussed earlier, Loving Care's repetition bears relevance to post-structuralist theories on the formation of the subject. Loving Care is repetitive both in and of itself (as Antoni performs the action of mopping) but also historically. It repeats conventional feminine behaviors which have gained their meaning over time. In Bodies That Matter, Judith Butler argues that "sex" is a normative "regulatory ideal" (2) which is materialized in practice through time. The reiteration of norms materializes sex without a voluntary, constructing subject. Expanding on the work of Foucault, Butler writes that performativity is discourse- reiterative, productive, regulatory, and constraining. It is within a pre-existing, reproducing matrix of gender relations that sex is materialized. For Butler, discourse forms but does not originate.

Unlike the assumed subject of post-structuralist thought, which is not traditionally theorized to come into social legibility through intentional action, the performance artist is intentional. One can argue that to bridge the performance artist's postmodern awareness with the post-structuralist metaphor of a totalizing matrix of social meaning, the use of Berlant's theory of genre is useful. When Antoni represents the assumption of a gender, she is doing so in regard to conventions which are recognizable, formed historically, regulatory, as would be discussed in post-structuralist work. Theorizing performance art as genre accounts for the affective aspects and motivations of the artist in the representation of the production of oneself as a gendered subject.

One of the affective aspects or motivations in the (performance of) the assumption of a gender: desire is discussed. Trans theory holds that the assumption of a gender can occur with an awareness of the discursive structures of sex difference. Trans theorists like Andrea Long Chu describe sense of belonging to a gender in terms of desire rather than a more abstract politics of identity. Long Chu describes her transition in terms of desiring to enact perceived tropes of feminine experience: "I doubt that any of us transition simply because we want to 'be' women, in some abstract, academic way. I certainly didn't. I transitioned for gossip and compliments, lipstick and mascara, for crying at the movies..." Like Long Chu, Antoni perceives a coherent fantasy of womanhood and consciously elects to participate in tropes she recognizes as constitutive of this social category. Art historical analysis of feminist performance art, as well as performance art enacted by other marginalized/non-normative bodies, can borrow from trans theory's ability to account for desire and intentionally in the production of the social subject.

Long Chu writes that "The primary function of gender identity as a political concept-and, increasingly, a legal one - is to bracket, if not to totally deny, the role of desire in the thing we call gender." To limit gender to the realm of the political is to regulate it, to delineate it as discrete. Long Chu writes that trans-exclusionary radical feminists (TERFs) can be described as "gender abolitionists", while to transition within the gender binary from one gender to another goes against a commitment to "the revolutionary dismantling of gender as a system of oppression". This line of thinking points to the primary concern for establishing a framework for feminist art, particularly, performance art- the awareness and affect that an artist brings to identity formation.

It is important to note that when Antoni performs an abstracted and acutely emotional version of the poststructuralist process of subjectification, she does not clearly problematize the gender binary. If one were to extend poststructuralist thinking, her assumption of this identity reproduces the categories of gender. Art historians must consider the artist's desire and awareness for the identity she transacts with. As Berlant notes in her definition of genre, one transacts with convention, experiencing pleasure in encountering what they expected.

Loving Care presents a knowable definition of womanhood through speaking to signifiers of a shared history. What trans theory can offer is sense of gender identity as not purely discrete, political, and individual, but in many ways, shared. It centers the generalities at hand in assuming gender identity for transgender and cisgender people alike. In regarding womanhood as a genre, it becomes understood as a heterogenous thing given a sense of coherence in its public representations. When Antoni mops the floor with her hair, she is experiencing pleasure in belonging to a fantasy of the coherent identity of "woman".

It is necessary for art historians to go beyond a straightforward application of post-structuralist theory in their approach to artwork. Artists and audiences are increasingly aware of how objects and behaviors become coded in social meaning. To consider art and artists to be unintentional in their reproduction of social meaning and institutions of power is to willfully disregard reality in favor of adherence to theory. The elaboration on Berlant's gender as genre can be applied to other social identities- the heterogeneity of racial, subcultural, and sexual experiences is similarly made coherent through discursive representation. Adopting the concept of genre from literary affect theory to address identity can allow for art historians to explore identity-centered art in the postmodern era.

\section{Acknowledgements}

Thank you to Dr. Julia Walker, whose commitment as a researcher and teacher made this work possible. 


\section{References:}

Berlant, Lauren Gail. The Female Complaint: The Unfinished Business of Sentimentality in American Culture. Durham: Duke University Press, 2008.

Long Chu, Andrea. "On Liking Women." N 1. January 03, 2018. Accessed March 22, 2018. https://nplusonemag.com/issue-30/essays/onliking-women/.

Synnott, Anthony. "Shame and Glory: A Sociology of Hair." The British Journal of Sociology 38, no. 3 (1987): 381-413. doi:10.2307/590695.

Krauss, Rosalind, Denis Hollier, Annette Michelson, Hal Foster, Silvia Kolbowski, Martha Buskirk, and Benjamin Buchloh. "The Reception of the Sixties." October 69 (1994): 3-21. doi:10.2307/778987.
Carson, Juli. "[Response to "The Reception of the Sixties"]." October 71 (1995): 144-45.

http://www.jstor.org/stable/778748.

Jones, Amelia. Body Art/Performing the Subject. Minneapolis: University of Minnesota Press, 1998.

Foucault, Michel, and Alan Sheridan. Discipline and Punish: The Birth of the Prison. London: Penguin Books, 1977.

Butler, Judith. 1993. Bodies that Matter: On the Discursive Limits of "Sex". New York: Routledge.

Schumacher, Bett. "The Woman Problem: Gender Displacement in the Art of Helen Frankenthaler." Woman's Art Journal 31, no. 2 (2010): 12-21. http://www.jstor.org/stable/41331080. 